\title{
Emodin inhibits the proliferation of papillary thyroid carcinoma by activating AMPK
}

\author{
WEILONG LI ${ }^{1 *}$, DONG WANG ${ }^{2 *}$, MEIJING LI $^{3}$ and BAOYUAN LI ${ }^{2}$ \\ Departments of ${ }^{1}$ Nuclear Medicine, ${ }^{2}$ Thyroid and ${ }^{3}$ Hepatobiliary, \\ The Affiliated Yantai Yuhuangding Hospital of Qingdao University, Yantai, Shandong 264000, P.R. China
}

Received July 9, 2020; Accepted March 25, 2021

DOI: $10.3892 /$ etm.2021.10509

\begin{abstract}
Emodin has been demonstrated to serve antitumor roles in a variety of tumor types, but the effect of emodin on papillary thyroid carcinoma and its molecular mechanisms remain unclear. In the current study, the role of emodin on papillary thyroid carcinoma was analyzed in vitro and in vivo. TPC-1 cells were treated with emodin $(0,10,25$ or $50 \mu \mathrm{M})$, and cell viability and apoptosis were detected using Cell Counting Kit-8 and flow cytometry, respectively. The expression levels of AMPK-associated proteins were examined using western blot analysis. To study the effect of emodin on the AMPK pathway, AMPK activator, AICAR and an AMPK inhibitor, Dorsomorphin, were used in TPC-1 cells. In vivo, mice were used to confirm the mechanism of emodin on papillary thyroid carcinoma. The results of the current study indicated that emodin treatment induced cell apoptosis and cell cycle arrest in TPC-1 cells. Furthermore, the inhibitory effect increased in a dose dependent manner. Following emodin treatment, the cell viability of TPC-1 cells was significantly decreased, and apoptosis rate increased $(\mathrm{P}<0.05)$. Furthermore, the expression levels of AMPK were increased in the emodin group compared with the control group $(\mathrm{P}<0.05)$. Similar effects were observed following AMPK activator treatment in TPC-1 cells. Following AMPK activator treatment, cell proliferation and the cell cycle were inhibited. Also, the AMPK inhibitor was demonstrated to mediate the therapeutic effect of emodin. In addition, the results of the present study demonstrated that emodin inhibited the MEK/ERK pathway. Additionally, the in vivo results of the current study were consistent with those in vitro. In conclusion, the current study demonstrated that the administration of Emodin inhibited the proliferation of papillary thyroid cancer cells via activating AMPK pathway activity.
\end{abstract}

Correspondence to: Dr Baoyuan Li, Department of Thyroid, The Affiliated Yantai Yuhuangding Hospital of Qingdao University, 20 Yuhuangding East Road, Yantai, Shandong 264000, P.R. China E-mail: baoyuanli1988@outlook.com

${ }^{*}$ Contributed equally

Key words: emodin, AMPK, papillary thyroid carcinoma, proliferation

\section{Introduction}

Thyroid carcinoma is a malignant tumor that is derived from thyroid epithelial cells and is a common endocrine malignancy (1). Compared with other types thyroid cancer, the incident rate of papillary thyroid carcinoma is highest, and is responsible for $90 \%$ of thyroid cancers. However, early detection of papillary thyroid carcinoma usually results in successful treatment and a favorable patient prognosis $(2,3)$. The incidence of papillary thyroid carcinoma has increased in the previous few decades, and the 5-year survival rate is 59\% in the advanced stage, worldwide (4). Therefore, identifying novel drugs and investigating the underlying mechanisms of this disease are important for improving patient overall survival.

Emodin, which is also known as 1,3,8-trihydroxy-6methy-anthraquinone, can be isolated from a number of Chinese medicinal herbs, including Rheum and Polygonum (5). A number of studies have demonstrated that emodin inhibits growth in multiple cancer types, including lung (5) and pancreatic cancer (6), and hepatocellular carcinoma (7). However, to the best of our knowledge, no research on the effect of emodin on papillary thyroid carcinoma has been previously performed. Previous reports have indicated that emodin serves an inhibitory role via AMPK and ERK in non-small cell lung cancer (8) and breast cancer (9).

AMPK has been revealed to serve an important role in cellular metabolic processes, including nutrient deprivation, mitochondrial dysfunction and oxidative stress (10). AMPK signaling has been indicated to be associated with cell differentiation, proliferation and the promotion of oncogenes and tumor growth, such as colorectal cancer and lung cancer $(11,12)$. However, whether AMPK serves a role in activation or inhibition during emodin treatment in papillary thyroid carcinoma requires clarification.

In the current study, whether emodin exerts a role in inhibiting the development of papillary thyroid carcinoma via AMPK was investigated further.

\section{Materials and methods}

Cell lines. TPC-1 cells were obtained from the China Center for Type Culture Collection (Wuhan, China). TPC-1 cells were cultured in RPMI-1640 medium (Thermo Fisher Scientific, Inc.) supplemented with 10\% FBS (Thermo Fisher Scientific, 


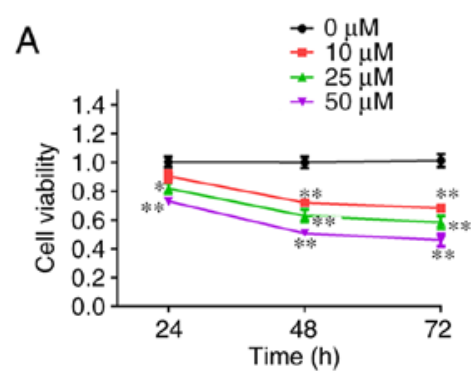

B

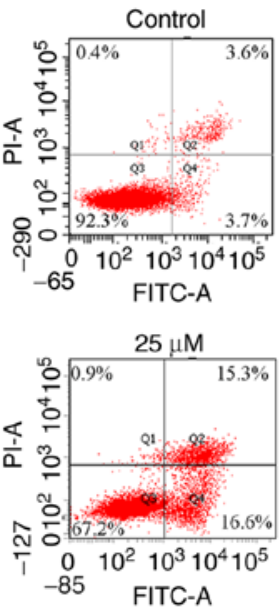

C
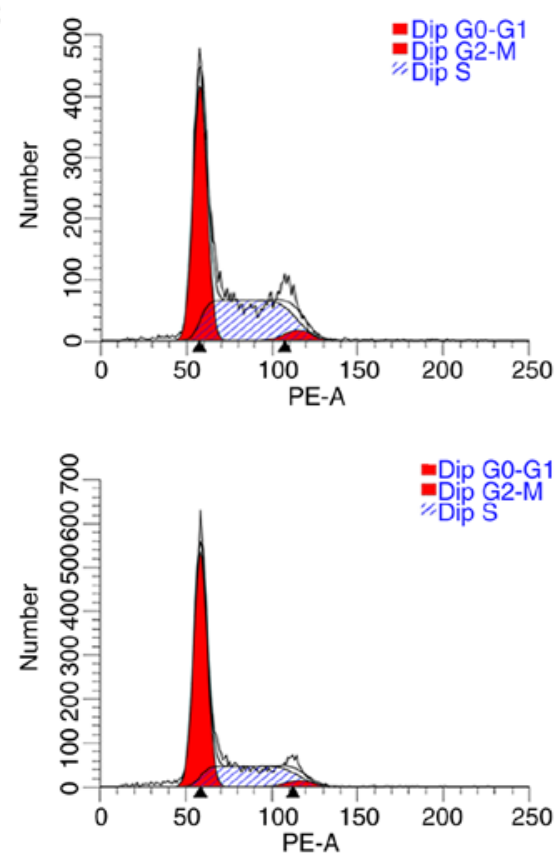
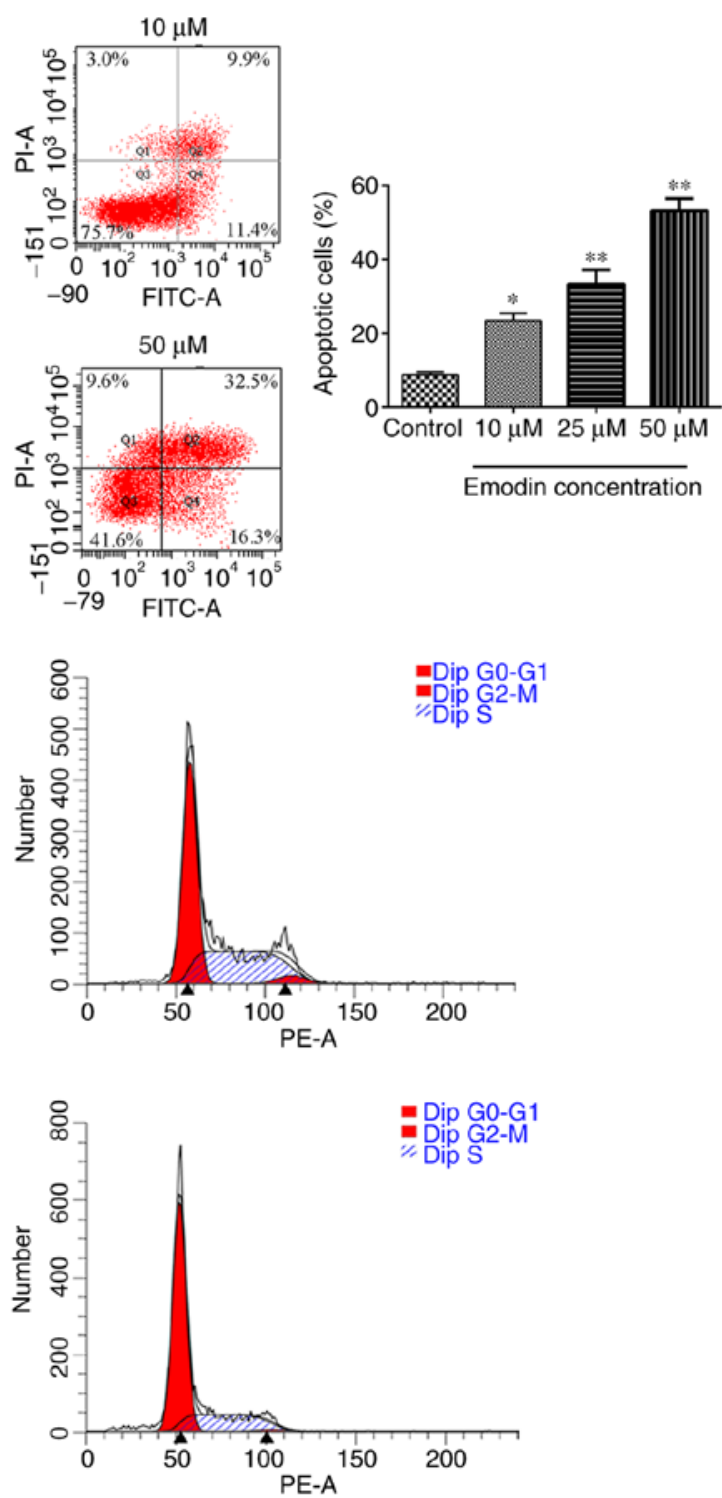

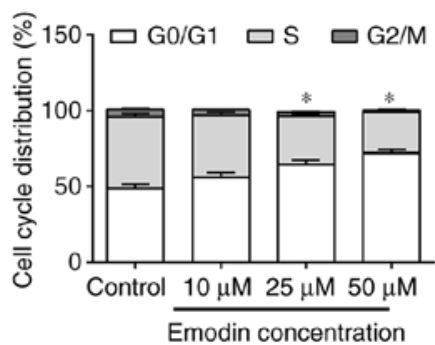

Figure 1. Emodin inhibits the proliferation and cell cycle of TPC-1 cells. (A) Cell counting kit-8 detection of cell viability of TPC-1 cells. (B) Flow cytometry to detect apoptosis. (C) Flow cytometry to detect the cell cycle. Data are presented as mean \pm standard deviation and analyzed by ANOVA. There were three parallel samples in each group. ${ }^{*} \mathrm{P}<0.05,{ }^{* *} \mathrm{P}<0.01$ vs. control.

Inc.), $100 \mathrm{U} / \mathrm{ml}$ penicillin and $100 \mathrm{mg} / \mathrm{ml}$ streptomycin (Thermo Fisher Scientific, Inc.). Cells were cultured at $37^{\circ} \mathrm{C}$ in $5 \% \mathrm{CO}_{2}$.

Cell grouping. To study the effect of emodin on the proliferation of TPC- 1 cells, 10,25 and $50 \mu \mathrm{M}$ emodin were added to TPC-1 cells for 24,48 and $72 \mathrm{~h}$ at $37^{\circ} \mathrm{C}$, respectively.

To further study the underlying mechanism of emodin on TPC-1 cells, cells were treated with different concentrations of emodin $(0,5,10,20,40$ or $80 \mu \mathrm{m})$ for $48 \mathrm{~h}$ at $37^{\circ} \mathrm{C}$, and the $\mathrm{IC}_{50}$ was calculated to be $49.01 \mu \mathrm{M}$ using SPSS 20.0 (IBM Corp.). Thus, emodin at a concentration of $50 \mu \mathrm{M}$ was used for subsequent experiments. The cells were divided into the control group, emodin treatment group (Emodin), AMPK activator group (AICAR), and emodin + AMPK inhibitor group (Combine). The cells of the control group were treated with PBS. In the emodin group, $50 \mu \mathrm{M}$ emodin was added to cells for $48 \mathrm{~h}$ at $37^{\circ} \mathrm{C}$. Cells in the AICAR group were treated with 

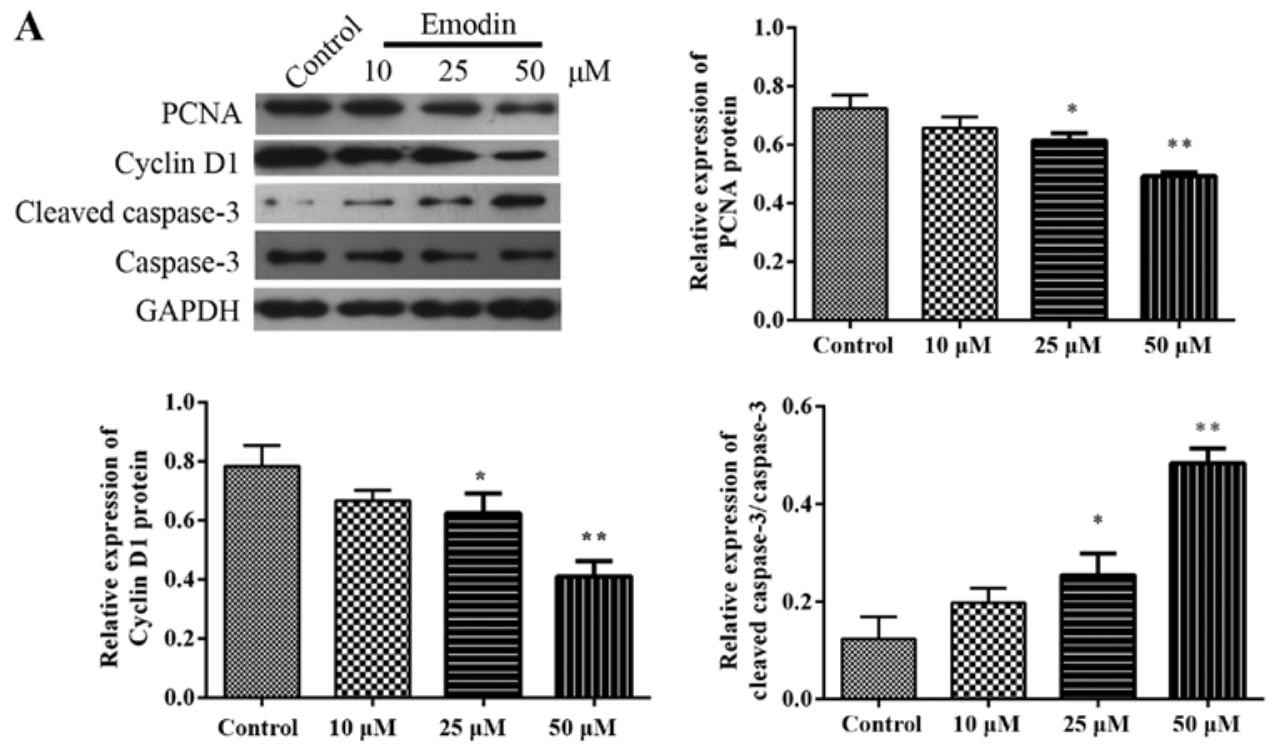

B
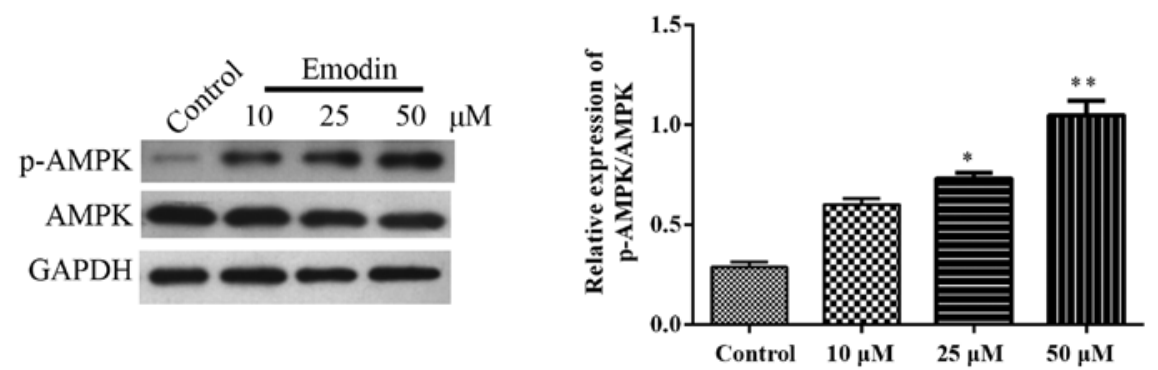

Figure 2. Emodin decreased the expression of PCNA, Cyclin D1, increased the expression of Cleaved-caspase-3, p-AMPK/AMPK in TPC-1 cells. (A) Western blot analysis to detect PCNA, Cyclin D1 and Cleaved-caspase-3/caspase-3; (B) Western blot analysis to detect p-AMPK/AMPK protein expression. Data are presented as mean \pm standard deviation and analyzed by ANOVA. There were three parallel samples in each group. ${ }^{*} \mathrm{P}<0.05,{ }^{* * *} \mathrm{P}<0.01$ vs. control. PCNA, proliferating cell nuclear antigen; $p$, phosphorylated.

$2 \mathrm{mM}$ AMPK activator (AICAR, Cell Signaling Technology, Inc.) for $48 \mathrm{~h}$ at $37^{\circ} \mathrm{C}(13)$. In the combination group, TPC-1 cells were treated with $50 \mu \mathrm{M}$ emodin and $10 \mu \mathrm{M}$ AMPK inhibitor (Dorsomorphin; cat. no. HY-13418A; MedChemExpress) for $48 \mathrm{~h}$ at $37^{\circ} \mathrm{C}$, as previously described (13). After $48 \mathrm{~h}$, the cells were collected and analyzed using Cell Counting Kit-8 (CCK-8), flow cytometry and western blot analysis.

CCK- 8 assay. TPC- 1 cells $\left(2 \times 10^{4}\right.$ cells $\left./ \mathrm{ml}\right)$ in each group were seeded into 96 -well plates and cultured at $37^{\circ} \mathrm{C}$ at $5 \% \mathrm{CO}_{2}$. After incubation for 24,48 and $72 \mathrm{~h}$, cells were incubated with $10 \mu$ l CCK-8 (Dojindo Molecular Technologies, Inc.) at $37^{\circ} \mathrm{C}$ for $4 \mathrm{~h}$ according to the manufacture's protocol. The supernatant was carefully discarded and the absorbance of each hole was measured at $450 \mathrm{~nm}$. Cell viability $=[$ Treatment (OD)]-Blank (OD)/[Control (OD)-Blank (OD)].

Flow cytometry. Following incubation for $48 \mathrm{~h}$, a AnnexinV-FITC/PI cell apoptosis detection kit (Meilunbio) was used to measure apoptotic cells. The cells $\left(2 \times 10^{5}\right)$ were centrifuged at $800 \mathrm{xg}$ for $5 \mathrm{~min}$ at $4^{\circ} \mathrm{C}$, collected and washed with PBS twice at $4^{\circ} \mathrm{C}$. The cells $\left(1 \times 10^{6} / \mathrm{ml}\right)$ were resuspended with $250 \mu \mathrm{l} 1 \mathrm{X}$ binding buffer. The cells $(100 \mu \mathrm{l})$ were subsequently added to a pipe with $5 \mu \mathrm{l}$ Annexin V-FITC and $10 \mu \mathrm{l}$ propidium iodide (PI; $20 \mu \mathrm{g} / \mathrm{ml}$ ). The mixture was cultured at $25^{\circ} \mathrm{C}$ for $15 \mathrm{~min}$ in darkness. The apoptotic rate was analyzed using a flow cytometer (Cytoflex3L8C; Beckman Coulter,
Inc.) and the results were analyzed using Cell Quest software version 2.0 (BD Biosciences).

Animals. A total of 36 specific pathogen free Balb/c female nude mice, (age, 5 weeks; weight, 18-20 g) were purchased from Beijing Weitong Lihua Experimental Animal Technology Co., Ltd. [license no. scxk (Jing) 20160006]. Food, water and bedding materials were sterilized, and the animals were provided with food and water ad libitum. Mice were housed in specifc pathogen free conditions, at $22-26^{\circ} \mathrm{C}$ with $40-70 \%$ humidity and $12 \mathrm{~h}$ light/dark cycles.

Xenograft model. TPC-1 cells were centrifuged at $800 \mathrm{x}$ g for $5 \mathrm{~min}$ at $4^{\circ} \mathrm{C}$, washed with sterile PBS three times and diluted. A total of $40 \mu \mathrm{l}$ cell suspension was added to $10 \mu \mathrm{l}$ phenol blue stain and cells were counted under a microscope. A cell suspension with a concentration of $5 \times 10^{8}$ cells $/ \mathrm{ml}$ was made. Cells $\left(\sim 0.2 \mathrm{ml} / 1 \times 10^{7}\right.$ cell $\left./ \mathrm{ml}\right)$ were inoculated subcutaneously under the right rear armpit of mice. The nude mice were randomly divided into four groups: Model group, emodin group, AICAR group and the combined group. In the emodin group, mice were intraperitoneally injected with emodin at $40 \mathrm{mg} / \mathrm{kg}$ (14). In AICAR group, mice were intraperitoneally injected with emodin at $40 \mathrm{mg} / \mathrm{kg}$ (14) and AICAR at $50 \mathrm{mg} / \mathrm{kg}$ (15). In the combination group, mice were intraperitoneally injected with emodin at $40 \mathrm{mg} / \mathrm{kg}$ and dorsomorphin at $0.2 \mathrm{mg} / \mathrm{kg}$ (16). In each group, mice were treated three times a week for a period 

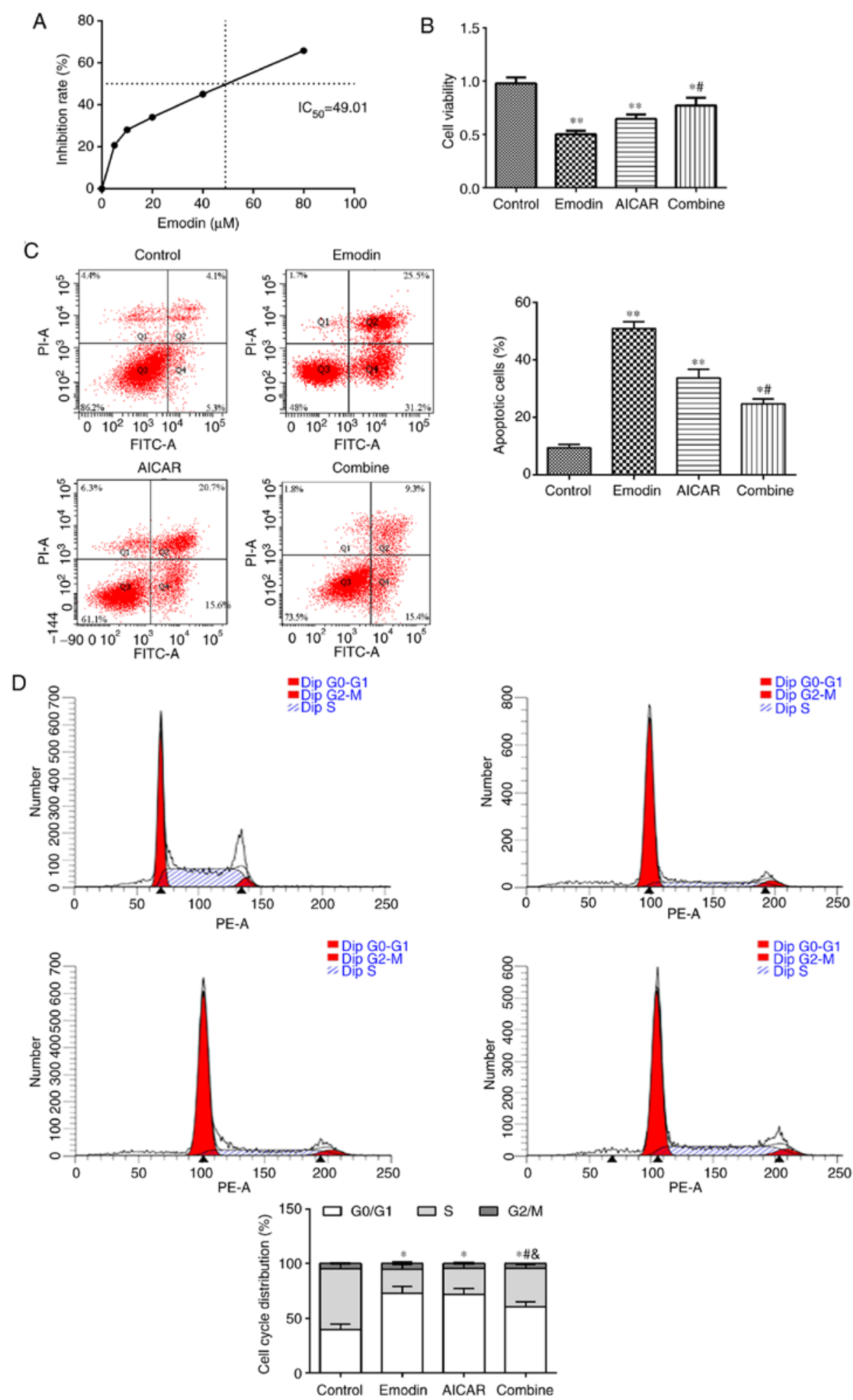

Figure 3. Emodin activates AMPK to affect the proliferation and cell cycle of TPC-1 cells. (A) The inhibition rate of emodin analyzed using CCK-8. (B) The cell viability analyzed using CCK-8. (C) Flow cytometry to detect apoptosis. (D) Flow cytometry to detect cell cycle. Data are presented as mean \pm standard deviation and analyzed by ANOVA. There were three parallel samples in each group. The Combine group comprised cells treated with emodin and dorsomorphin. ${ }^{*} \mathrm{P}<0.05,{ }^{* *} \mathrm{P}<0.01$ vs. control group, ${ }^{\#} \mathrm{P}<0.05$ vs. emodin group; ${ }^{\text {}} \mathrm{P}<0.05$ vs. AICAR group. CCK- 8 , Cell Counting Kit- 8 .

of two weeks. In the model group, mice were intraperitoneally injected with normal saline. The tumor volume $(\mathrm{V})=\left(\mathrm{axb}^{2}\right) / 2$ was calculated every week. The tumor volume was observed every week for 4 weeks. The health and behaviors of animals were monitored every day, including diet, weight, mental states and death. There was no death observed during the experiment. The maximum percentage of body weight loss was $10.2 \%$ in animals from start to endpoint. After a period of 28 days, $3 \%$ pentobarbital sodium $(40 \mathrm{mg} / \mathrm{kg})$ was intraperitoneally injected, and the nude mice were sacrificed via cervical dislocation. Five minutes after cardiac arrest, death was confirmed. The tumor was subsequently separated and weighed. Partial tumor sections were 
A

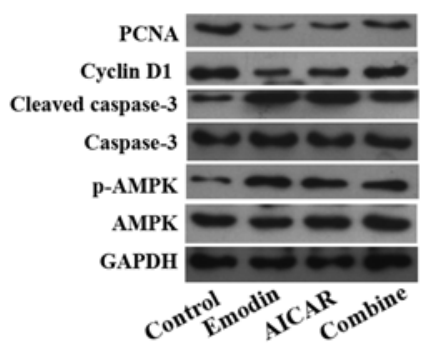

B

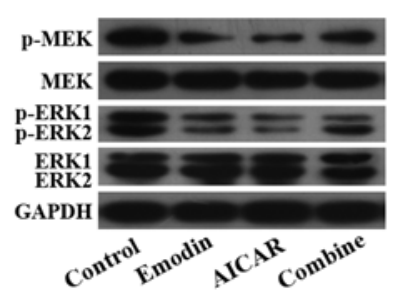

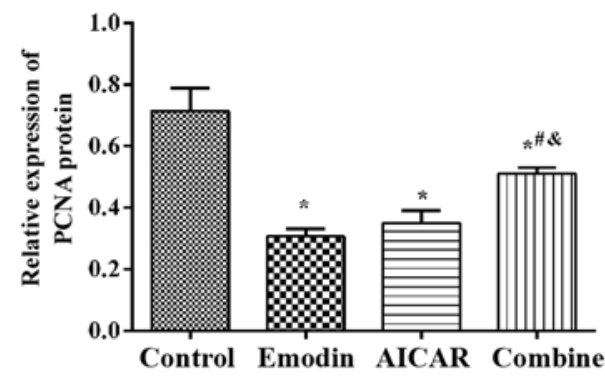
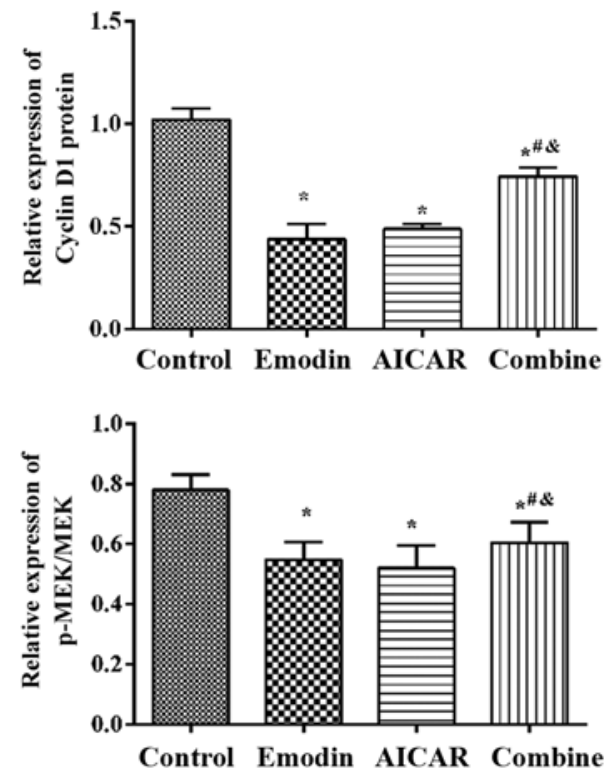
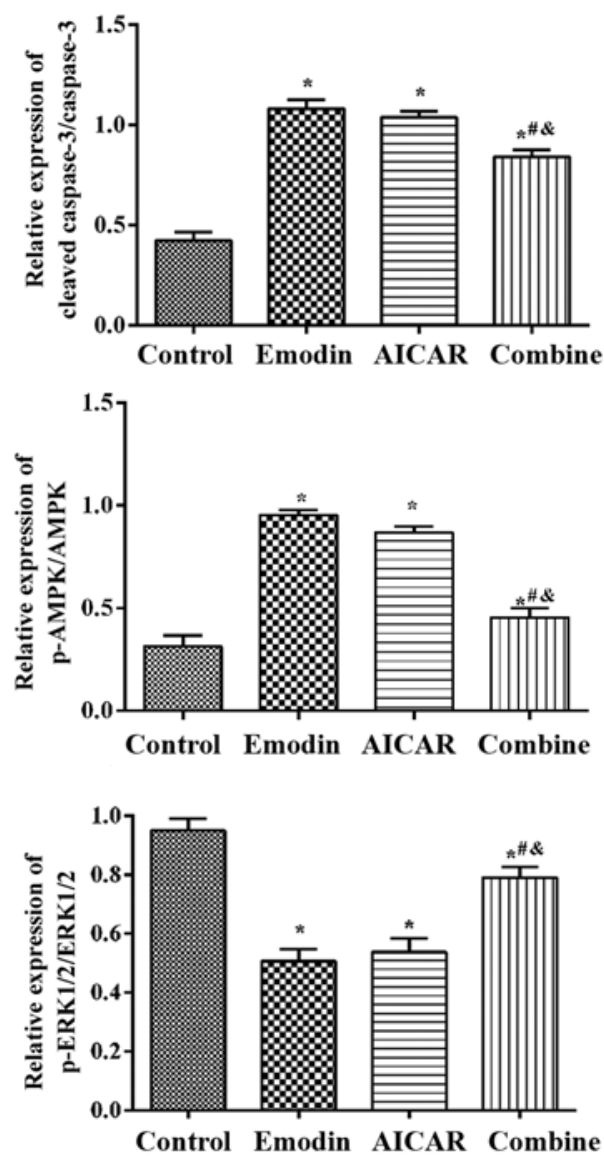

Figure 4. Emodin activates AMPK to affect the MEK-ERK pathway in TPC-1 cells. (A) Western blot analysis to detect PCNA, Cyclin D1, Cleaved-caspase-3/caspase-3, p-AMPK and AMPK proteins expression. (B) Western blot to detect p-MEK/MEK, p-ERK1/2/ERK1/2 proteins expression. GAPDH was used as the internal control. Data are presented as mean \pm standard deviation and analyzed by ANOVA. There were three parallel samples in each group. ${ }^{*} \mathrm{P}<0.05$ vs. control group, ${ }^{\#} \mathrm{P}<0.05$ vs. emodin group; ${ }^{\circledR} \mathrm{P}<0.05$ vs. AICAR group. PCNA, proliferating cell nuclear antigen; p, phosphorylated.

stored at $-80^{\circ} \mathrm{C}$ for use in western blot analysis, and partially tumor sections were fixed with $4 \%$ paraformaldehyde at $25^{\circ} \mathrm{C}$ for $24 \mathrm{~h}$ for use in the TUNEL assay.

TUNEL. Tumor sections were $4 \mu \mathrm{m}$ thick. After regular dewaxing with xylene and gradient ethanol, the sections were assessed using a Situ TUNEL Apoptosis Detection kit (cat. no. G001-2-1; Nanjing Jiancheng Bioengineering Institute) according to the manufacturer's protocol. In brief, the sections were treated with $50 \mu \mathrm{l} \mathrm{TdT}$ reaction solution for $60 \mathrm{~min}$ at $37^{\circ} \mathrm{C}$, then washed with PBS for in triplicate. A total of $50 \mu 1$ streptavidin-HRP solution was added for $30 \mathrm{~min}$ at $37^{\circ} \mathrm{C}$ in the dark, after which the solution was washed three times with PBS for 3 times. Samples were then treated with $80 \mu 1$ DAB solution at room temperature for $10 \mathrm{~min}$. At the end of staining procedure, the number of TUNEL positive cells was observed under the microscope. A total of five fields of view were randomly selected, and the number of TUNEL positive cells was counted. The nuclei of apoptotic cells were stained brown. Apoptotic index $=$ (number of apoptotic positive cells/total cells) $\mathrm{x} 100 \%$.

Western blot analysis. Total protein of the TPC-1 cells or tissues in each group was extracted using a Tissue or Cell Total Protein Extraction kit (cat. no. BC3710; Beijing Solarbio Science \& Technology Co., Ltd.) and the concentration of proteins was assessed using a BCA protein quantification kit (cat. no. 23225; Thermo Fisher Scientific, Inc.). Samples (50 $\mu \mathrm{g} /$ lane) were separated using 12\% SDS-PAGE (Bio-Rad Laboratories, Inc.) and transferred to a PVDF membrane (Bio-Rad Laboratories, Inc.). Skim milk powder (5\%) was used to block membranes for $1 \mathrm{~h}$ at $4^{\circ} \mathrm{C}$. The primary antibodies were diluted with 5\% BSA and incubated with samples at $4^{\circ} \mathrm{C}$ overnight. The primary antibodies used were as follows: Rabbit anti-human proliferating cell nuclear antigen (PCNA) antibody (1:700; cat. no. orb386383; Biorbyt, Ltd.), anti-Cleaved caspase-3 antibody (1:500; cat. no. ab49822; Abcam), caspase-3 antibody (1:500; cat. no. ab13847; Abcam), anti-Cyclin D1 antibody (1:200; cat. no. ab16663; Abcam), anti-phosphorylated (p-)AMPKa1 (Thr172) Antibody (1:1,000; cat. no. orb99303; Biorbyt, Ltd.), anti-AMPKa1 Antibody (1:1,000; cat. no. orb338932; Biorbyt, Ltd.), anti-ERK1/2 antibody (1:600; cat. no. orb106403; Biorbyt, Ltd.), anti-p-ERK1/2 antibody (1:600; Biorbyt, Ltd.), anti-MEK antibody (1:600; cat. no. orb38774; Biorbyt, Ltd.), anti-p-MEK antibody (1:600; cat. no. orb106207; Biorbyt, Ltd.) and GAPDH antibody (1:8,000; cat. no. orb555879; Biorbyt, Ltd.). The secondary antibody was HRP-labeled anti-rabbit IgG (1:1,800; cat. no. ab6721; Abcam) for $1 \mathrm{~h}$ at $4^{\circ} \mathrm{C}$. GAPDH was used as the internal control. Blots were visualized on X-ray film using the enhanced chemiluminescence detection system (Cytiva). Densitometric analysis of the bands for the expression of protein was performed using Image J 6.0 (National Institutes of Health). 
A

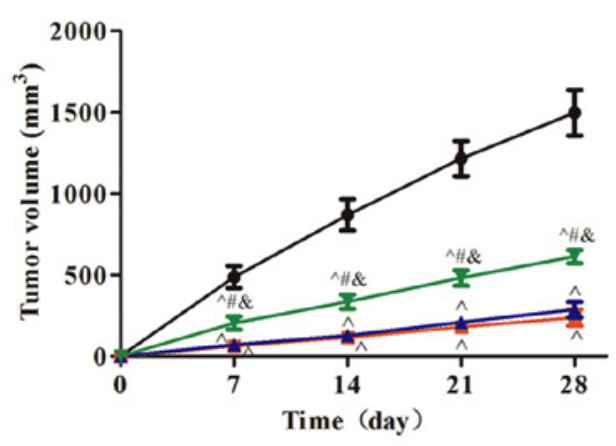

B

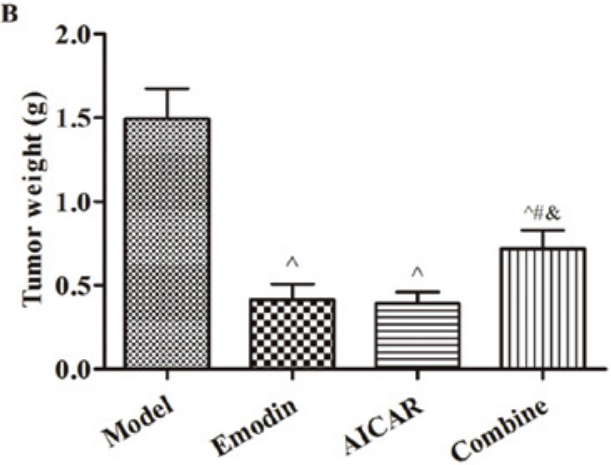

C

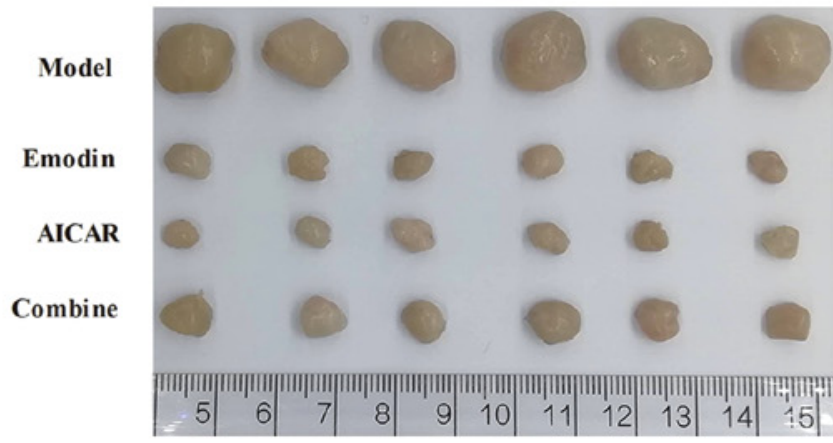

D
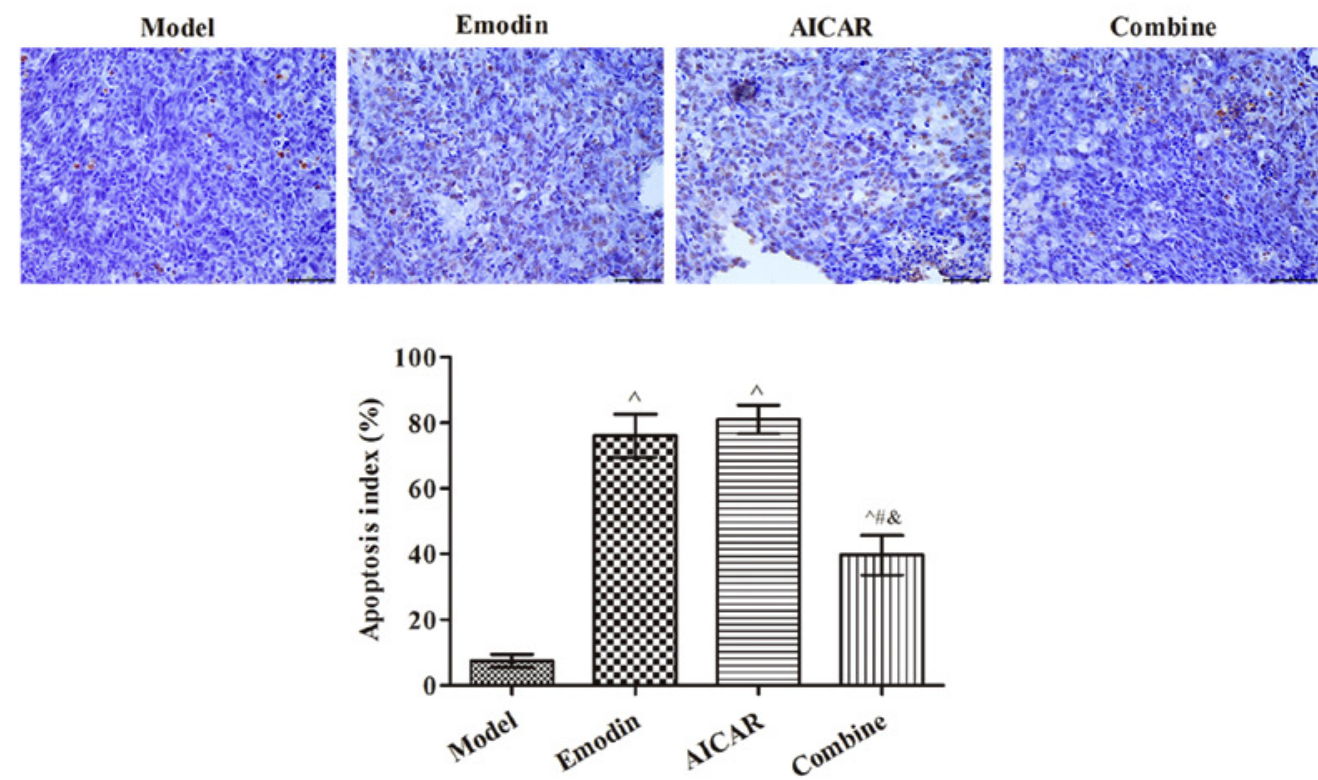

Figure 5. Emodin activates AMPK to suppress tumor growth. (A) Tumor volume. (B) Tumor weight. (C) Tumor images. (D) Apoptosis cells were analyzed using a TUNEL kit in tumor tissues (magnification, $\mathrm{x} 400$ ). Data are presented as mean \pm standard deviation and analyzed by ANOVA. There were six mice in each group. The Combine group comprised cells treated with emodin and dorsomorphin. ${ }^{\wedge} \mathrm{P}<0.05$ vs. model group, ${ }^{\text {}} \mathrm{P}<0.05$ vs. emodin group; ${ }^{\text {\& }} \mathrm{P}<0.05$ vs. AICAR group.

Statistical analysis. The statistical data in the current study was analyzed using SPSS 20.0 statistical software (IBM Corp.). The data are presented as mean \pm standard deviation. Among groups, differences were analyzed using ANOVA and followed by Tukey's post hoc test. $\mathrm{P}<0.05$ was considered to indicate a statistically significant difference.

\section{Results}

Emodin inhibits proliferation of papillary thyroid cells. Compared with the control group, cell viability was significantly decreased following treatment with varied doses of emodin (Fig. 1A). Additionally, the proportion of cells in the apoptosis and $G_{0} / G_{1}$ phase increased significantly, and the proportion of cells in the $\mathrm{S}$ phase decreased $(\mathrm{P}<0.05$; Fig. $1 \mathrm{~B}$ and $\mathrm{C})$. These data indicated that emodin inhibited TPC-1 cell proliferation and the cell cycle.

Emodin activates the phosphorylation of the AMPK pathway. Fig. 2 indicated that the expression levels of PCNA (Fig. 2A) and Cyclin D1 (Fig. 2A) protein were decreased, and the expression of Cleaved-caspase-3/caspase-3 (Fig. 2A) and 
A

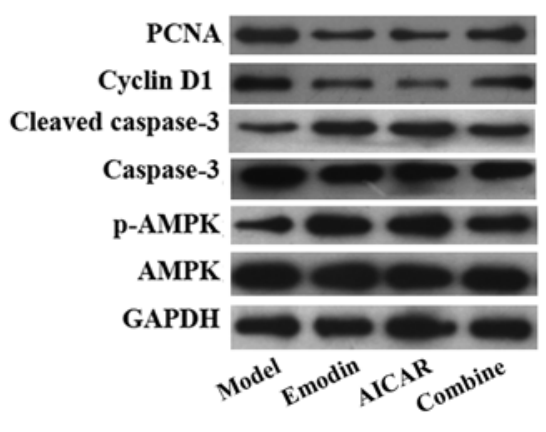

B

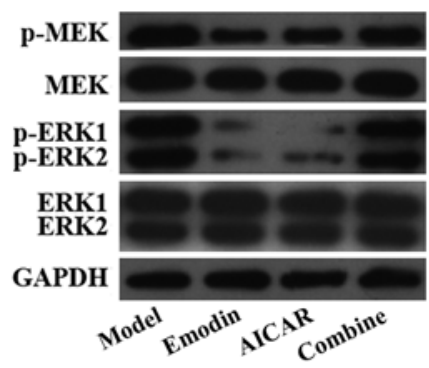

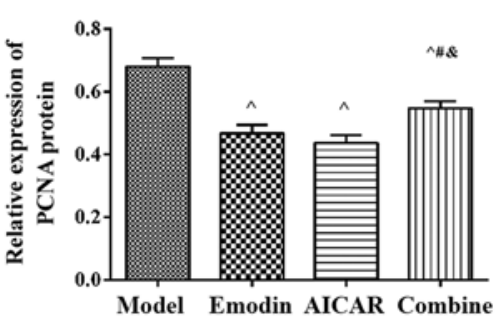
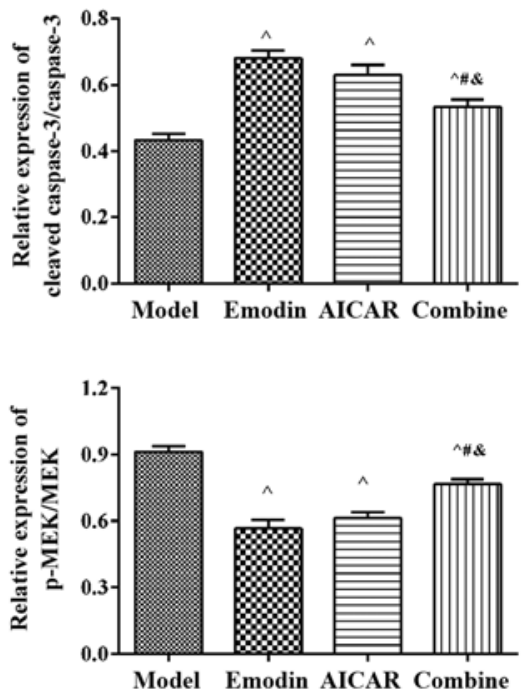
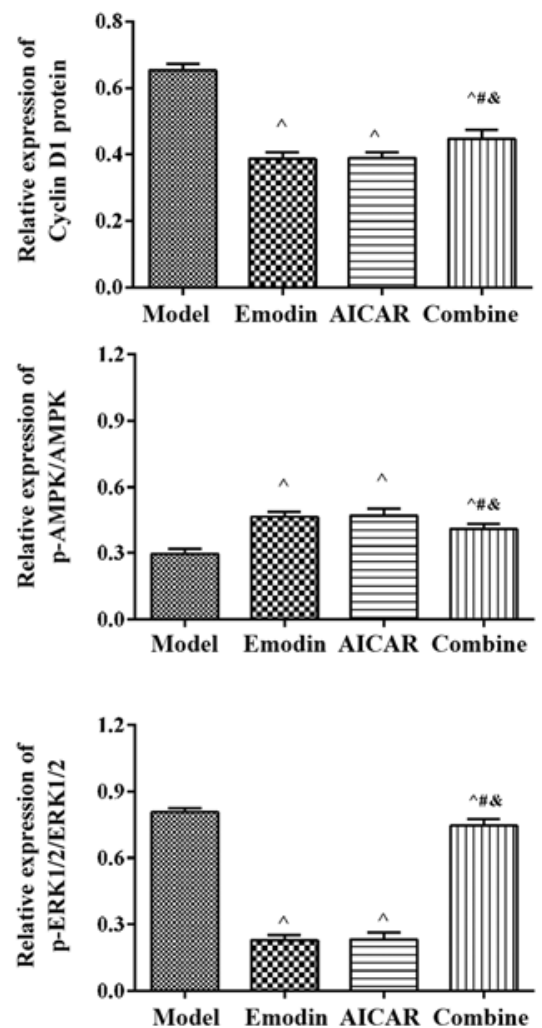

Figure 6. Emodin activates AMPK to suppress the MEK-ERK pathway in vivo. (A) Western blot analysis to detect PCNA, Cyclin D1, Cleaved-caspase-3/caspase-3 and p-AMPK/AMPK proteins expression. (B) Western blot analysis to detect p-MEK/MEK, p-ERK1/2/ERK1/2 protein expression. Data are presented as mean \pm standard deviation and analyzed by ANOVA. There were six mice in each group. The Combine group comprised cells treated with emodin and dorsomorphin. ${ }^{\wedge} \mathrm{P}<0.05$ vs. model group; ${ }^{~} \mathrm{P}<0.05$ vs. emodin group; ${ }^{\circledR} \mathrm{P}<0.05$ vs. AICAR group. PCNA, proliferating cell nuclear antigen; $\mathrm{p}$, phosphorylated.

p-AMPK/AMPK protein (Fig. 2B) were upregulated following treatment with 25 and $50 \mu \mathrm{M}$ emodin when compared with the control group $(\mathrm{P}<0.05)$. These data suggested that emodin may serve a role in the expression of the AMPK pathway and the inhibition of TPC-1 cell proliferation and the cell cycle.

Emodin activates the AMPK pathway to affect proliferation papillary thyroid cells. In order to elucidate whether emodin affects proliferation and the cell cycle in TPC-1 cells via the AMPK pathway, AMPK inhibitor (Dorsomorphin) and activator (AICAR) were used to perform subsequent experiments. The experimental results are presented in Fig. 3. The $\mathrm{IC}_{50}$ of emodin was analyzed in Fig. 3A. When compared with the control group, the proliferation of cells in the emodin and AICAR group were reduced (Fig. 3A), the apoptosis rate in TPC-1 cells was significantly increased and the distribution was also markedly raised in the $\mathrm{G}_{0} / \mathrm{G}_{1}$ phase $(\mathrm{P}<0.05$; Fig. $3 \mathrm{C}$ and $\mathrm{D})$. Compared with the emodin group, the malignant biological behavior of the combined group was increased $(\mathrm{P}<0.05)$.

Emodin activates AMPK to affect the MEK-ERK pathway. Fig. 4A indicated that PCNA and Cyclin D1 proteins levels were downregulated, and the levels of Cleaved-caspase-3/caspase-3 and $\mathrm{p}$-AMPK/AMPK proteins were upregulated in the emodin and AICAR group when compared with the control group $(\mathrm{P}<0.05)$. However, there was no significant difference between the two groups. Fig. 4B indicated that when compared with the control group, p-ERK1/2 and p-MEK expression in the emodin and AICAR group were decreased $(\mathrm{P}<0.05)$. In contrast to the emodin and AICAR group, the two proteins in the combined group were markedly increased $(\mathrm{P}<0.05)$. These results indicate that emodin activated AMPK to downregulate the MEK-ERK pathway in TPC-1 cells.

Emodin suppresses tumor growth via activating AMPK. The mice model of tumor xenograft was established using TPC-1 cells. Nude mice were randomly divided into the model, emodin, AICAR and combined group. The tumor volume and tumor weight in each group are presented in Fig. 5A-C. Consistent with the in vitro experiment, the results revealed that emodin significantly suppressed tumor growth in vivo when compared with the model mice $(\mathrm{P}<0.05)$. The AMPK activator served a similar role to emodin, which suppressed tumor growth. However, administration of the AMPK inhibitor weakened the suppression of tumor growth caused by emodin $(\mathrm{P}<0.05)$. Furthermore, the apoptosis index in tumor tissues of each group indicated that emodin increased the number of apoptotic cells compared with the model mice $(\mathrm{P}<0.05$; Fig. 5D). These data suggested that emodin may suppress papillary thyroid carcinoma via activating AMPK.

Emodin suppresses the MEK-ERK pathway via activating $A M P K$. As presented in Fig. 6A, the expression of PCNA and Cyclin D1 significantly decreased, while the expression of Cleaved-caspase-3/caspase-3 and p-AMPK/AMPK increased in the emodin and AICAR group compared with the model 
group $(\mathrm{P}<0.05)$. In addition, the expression of $\mathrm{p}$-ERK/ERK and $\mathrm{p}-\mathrm{MEK} / \mathrm{MEK}$ was significantly downregulated following emodin or AICAR administration $(\mathrm{P}<0.05$; Fig. 6B). In contrast to the emodin group, the effect of emodin was significantly lower in the combined group $(\mathrm{P}<0.05)$. These data revealed that emodin may suppress the MEK-ERK pathway via activating AMPK.

\section{Discussion}

It is well known that emodin inhibits tumor growth in a number of different cancer types, such as pancreatic cancer, hepatocellular carcinoma and breast cancer $(6,7,9)$. It has also been reported that emodin can suppress PCNA expression in some tumor cells, including those in cervical cancer (17). PCNA binds with human DNA polymerase $\delta$ to serve a role in DNA duplication and repair, and is usually a marker for cell proliferation and DNA replication (7). Consistent with a previous study (17), the current study demonstrated that emodin suppressed PCNA expression in TPC-1 cells. Cell cycle interruption is a major feature of tumor transformation and the status of the cell cycle represents a prognostic index for cancer (18). Cyclin-D1, which is a regulator of the $G_{1} / S$ cell cycle, serves an essential role in tumor progression, contributes to tumor growth and resists anticancer drugs (18). It was therefore hypothesized that emodin would reduce the expression of Cyclin-D1 expression in TPC-1 cells and in a xenograft model.

A number of studies have demonstrated that AMPK is a cellular energy and nutritional status sensor in eukaryotic cells that is associated with the mechanism targets of rapamycin complex-1 (19-21). AMPK is likely to be the earliest signaling pathway in a number of evolutionary processes within eukaryotes (20). AMPK activation raises catabolism production (ATP production) and represses anabolic rate (ATP utilization). AMPK not only maintains the energy balance within the cell, but also regulates energy metabolism throughout the body (20). Due to its pivotal role in maintaining energy homeostasis, AMPK has the potential to become a underlying target for the treatment of metabolic diseases, which makes it an interesting study target (21). In the present study, emodin was indicated to be a cancer suppressor, and was revealed to suppress the proliferation and cell cycle of TPC- 1 cells, and to promote cell apoptosis. Furthermore, the current study suggested that emodin may activate the AMPK pathway to inhibit cell proliferation and the cell cycle in human papillary thyroid carcinoma cells.

The MEK-ERK signaling cascade is activated by tyrosine kinase, which is linked by its homologous growth factor receptor under normal physiological conditions (22). MEK, which is a tyrosine-threonine kinase, is being widely studied as a potential drug target (22). A number of previous studies have demonstrated that emodin may inhibit cancer proliferation in a number of cancers via the ERK pathway, including in hepatocellular carcinoma (23), non-small cell lung cancer (8) and breast cancer (9). The results of the current study revealed that in human papillary thyroid carcinoma cells, emodin decreased p-ERK1/2 and p-MEK expression by activating AMPK, both in vitro and in vivo.

The association between emodin and AMPK pathway remains to be further elucidated in future research. Although the present study suggested that emodin may activate AMPK to inhibit the activity of MEK-ERK pathway, the specific mechanism governing this is still unclear and requires further study. In conclusion, the results of the current study suggested that emodin inhibited the proliferation of papillary thyroid cancer cells, and the mechanism may be associated with the activation of AMPK.

\section{Acknowledgements}

Not applicable.

\section{Funding}

The current study was supported by the Project of Yantai Science and Technology Plan (grant no. 2018SFGY113).

\section{Availability of data and materials}

The datasets used and/or analyzed during the current study are available from the corresponding author on reasonable request.

\section{Authors' contributions}

WL and DW carried out the experimental work and the data collection and interpretation. WL, ML and DW participated in the design and coordination of experimental work, and acquisition of data. WL, DW and BL participated in the data collection, analysis of data and preparation of the manuscript. All authors read and approved the final manuscript.

\section{Ethics approval and consent to participate}

The experiments were approved by The Animal Protection and Use Committee of the Affiliated Yantai Yuhuangding Hospital of Qingdao University (approval no. 2020-161).

\section{Patient consent for publication}

Not applicable.

\section{Competing interests}

The authors declare that they have no competing interests.

\section{References}

1. Sak SD: Variants of papillary thyroid carcinoma: Multiple faces of a familiar tumor. Turk Patoloji Derg 31 (Suppl 1): S34-S47, 2015.

2. Lam AK and Saremi N: Cribriform-morular variant of papillary thyroid carcinoma: A distinctive type of thyroid cancer. Endocr Relat Cancer 24: R109-R121, 2017.

3. Ambrosi F, Righi A, Ricci C, Erickson LA, Lloyd RV and Asioli S: Hobnail variant of papillary thyroid carcinoma: A literature review. Endocr Pathol 28: 293-301, 2017.

4. Stoffer SS: Werner \& Ingbar's The Thyroid: A Fundamental and Clinical Text. 7th edition. Lippincott Williams \& Wilkins, Philadelphia, PA, 1996.

5. Su J, Yan Y, Qu J, Xue X, Liu Z and Cai H: Emodin induces apoptosis of lung cancer cells through ER stress and the TRIB3/NF-кB pathway. Oncol Rep 37: 1565-1572, 2017.

6. Li N, Wang C, Zhang P and You S: Emodin inhibits pancreatic cancer EMT and invasion by up-regulating microRNA-1271. Mol Med Rep 18: 3366-3374, 2018. 
7. Kim YS, Lee YM, Oh TI, Shin DH, Kim GH, Kan SY, Kang H, Kim JH, Kim BM, Yim WJ and Lim JH: Emodin sensitizes hepatocellular carcinoma cells to the anti-cancer effect of sorafenib through suppression of cholesterol metabolism. Int J Mol Sci 19: $3127,2018$.

8. Tang Q, Wu J, Zheng F, Hann SS and Chen Y: Emodin increases expression of insulin-like growth factor binding protein 1 through activation of MEK/ERK/AMPK $\alpha$ and interaction of PPAR $\gamma$ and Sp1 in lung cancer. Cell Physiol Biochem 41: 339-357, 2017.

9. Tseng HS, Wang YF, Tzeng YM, Chen DR, Liao YF, Chiu HY and Hsieh WT: Aloe-emodin enhances tamoxifen cytotoxicity by suppressing Ras/ERK and PI3K/mTOR in breast cancer cells. Am J Chin Med 45: 337-350, 2017.

10. Tang Q, Zhao S, Wu J, Zheng F, Yang L, Hu J and Hann SS Inhibition of integrin-linked kinase expression by emodin through crosstalk of AMPK $\alpha$ and ERK1/2 signaling and reciprocal interplay of Sp1 and c-Jun. Cell Signal 27: 1469-1477, 2015.

11. Yu H, Xie Y, Zhou Z, Wu Z, Dai X and Xu B: Curcumin regulates the progression of colorectal cancer via LncRNA NBR2/AMPK pathway. Technol Cancer Res Treat 18: 1533033819870781, 2019.

12. Chen D, Wu YX, Qiu YB, Wan BB, Liu G, Chen JL, Lu MD and Pang QF: Hyperoside suppresses hypoxia-induced A549 survival and proliferation through ferrous accumulation via AMPK/HO-1 axis. Phytomedicine 67: 153138, 2020.

13. Samuels JS, Shashidharamurthy R and Rayalam S: Novel anti-obesity effects of beer hops compound xanthohumol: Role of AMPK signaling pathway. Nutr Metab (Lond) 15: 42, 2018

14. Wu CC, Chen MS, Cheng YJ, Ko YC, Lin SF, Chiu IM and Chen JY: Emodin inhibits EBV reactivation and represses NPC tumorigenesis. Cancers (Basel) 11: 1795, 2019.

15. Tsai WL, Hsu CN and Tain YL: Whether AICAR in pregnancy or lactation prevents hypertension programmed by high saturated fat diet: A pilot study. Nutrients 12: 448, 2020.
16. Hasanvand A, Amini-Khoei H, Hadian MR, Abdollahi A, Tavangar SM, Dehpour AR, Semiei E and Mehr SE: Anti-inflammatory effect of AMPK signaling pathway in rat model of diabetic neuropathy. Inflammopharmacology 24 : 207-219, 2016.

17. Guo JM, Xiao BX, Liu Q, Zhang S, Liu DH and Gong ZH: Anticancer effect of aloe-emodin on cervical cancer cells involves $\mathrm{G} 2 / \mathrm{M}$ arrest and induction of differentiation. Acta Pharmacol Sin 28: 1991-1995, 2007.

18. Hsu LC, Tu HF, Hsu FT, Yueh PF and Chiang IT: Beneficial effect of fluoxetine on anti-tumor progression on hepatocellular carcinoma and non-small cell lung cancer bearing animal model. Biomed Pharmacother 126: 110054, 2020.

19. Yasemin S, Peterson TR, Shaul YD, Lindquist RA, Thoreen CC, Bar-Peled L and Sabatini DM: The Rag GTPases bind raptor and mediate amino acid signaling to mTORC1. Science 320: 1496-1501, 2008.

20. Hardie DG: AMPK-sensing energy while talking to other signaling pathways. Cell Metab 20: 939-952, 2014.

21. Carling D: AMPK signalling in health and disease. Curr Opin Cell Biol 45: 31-37, 2017.

22. Poulikakos PI, Zhang C, Bollag G, Shokat KM and Rosen N: RAF inhibitors transactivate RAF dimers and ERK signalling in cells with wild-type BRAF. Nature 464: 427-430, 2010.

23. Lin W, Zhong M, Yin H, Chen Y, Cao Q, Wang C and Ling C: Emodin induces hepatocellular carcinoma cell apoptosis through MAPK and PI3K/AKT signaling pathways in vitro and in vivo. Oncol Rep 36: 961-967, 2016

This work is licensed under a Creative Commons Attribution-NonCommercial-NoDerivatives 4.0 International (CC BY-NC-ND 4.0) License. 